\title{
Pre-treatment with sodium silicate, sodium hydroxide, ionic liquids or methacrylate resin to reduce the set-recovery and increase the hardness of surface-densified Scots pine
}

\author{
Benedikt Neyses ${ }^{(1)}$, \\ Lauri Rautkari ${ }^{(2)}$, \\ Akio Yamamoto ${ }^{(2)}$, \\ Dick Sandberg ${ }^{(1)}$
}

\begin{abstract}
The hardness of the outer regions of solid wood can be improved by surface densification, and this opens up new fields of application for low-density species. So far, surface densification relies on time- and energy-consuming batch processes, and this means that the potential advantages over more expensive hardwood species or non-renewable materials are reduced. Using fossil-based plastics or applying wood densification processes with a high energy consumption has adverse effects on the environment. In a previous study, it was shown that the surface of wood can be densified by a continuous high-speed process, adopting a roller pressing approach. The desired density profiles could be obtained at process speeds of up to $80 \mathrm{~m} \mathrm{~min}^{-1}$, but an equally simple and fast method to eliminate the moisture-induced set-recovery of the densified wood cells is still required. For this reason, the goal of the present study was to evaluate the effect on the set-recovery and hardness of surface-densified Scots pine after a fast pre-treatment with solutions of sodium silicate, sodium hydroxide, methacrylate resin, and ionic liquids. The Scots pine specimens were pre-treated by applying the chemical treatment and impregnation agents to the wood surface with a paper towel, before the specimens were densified. For each type of treatment, 15 specimens were densified in a hot press. The set-recovery was measured after two wet-dry cycles, and 30 Brinell hardness measurements were carried out on each group of specimens. In general, the effect of the treatments on the set-recovery was rather low. lonic liquid solutions appear to work as a strong plasticiser and the treatment led to a reduction in set-recovery by $25 \%$. The treatments with sodium silicate, ionic liquids and methacrylate resin led to a greater hardness than in untreated and densified specimens. Further experiments are needed to improve the depth of penetration of the treatment solutions into the wood surface, as this was identified as one of the main causes of the rather weak effects.
\end{abstract}

Keywords: Water Glass, Compression, Wood Modification, Surface Treatment, Ionic Liquid, Sodium Hydroxide, Methacrylate Resin, Sodium Silicate

\section{Introduction}

Beginning in the middle of the $20^{\text {th }}$ century, the amount of resources used by the human population started to exceed the long-term resource capacity of the earth. Today, a growing number of people recognise that this trend cannot go on forever. The available resources need to be used
(1) Luleå University of Technology, Wood Science and Engineering,Forskargatan 1, 93187 Skellefteå (Sweden); (2) Aalto University, Department of Bioproducts and Biosystems, Vuorimiehentie 1, 02150 Espoo (Finland)

@ Benedikt Neyses (benedikt.neyses@ltu.se)

Received: Feb 01, 2017 - Accepted: Jul 04, 2017

Citation: Neyses B, Rautkari L, Yamamoto A, Sandberg D (2017). Pre-treatment with sodium silicate, sodium hydroxide, ionic liquids or methacrylate resin to reduce the set-recovery and increase the hardness of surface-densified Scots pine. iForest 10: 857-864. - doi:

10.3832/ifor2385-010 [online 2017-10-26]

Communicated by: Giacomo Goli sustainably and the use of renewable resources, such as wood, is growing in popularity. Even though wood is widely available all over the world and will remain so in the future if managed properly, certain wood species are largely associated with cost-driven products. This applies especially to many softwood species, such as pine or spruce, which are predominantly found in boreal and temperate forests. Through wood modification it is possible to improve the properties of these wood species, so that they can be used for performance-driven products.

The first patents for compressed wood were issued to Sears (1900) in the United States. Various techniques were developed in the course of the $20^{\text {th }}$ century, including mechanical and hydrostatic compression with added steam and/or heat, but these 
never became a commercial success. In Europe, a German patent was issued in 1923 (Holzveredelung 1923) for the permanent fixation of densified wood by chemical treatment, but without mentioning the temperature $(T)$ or pressure $(P)$ used in the process. In 1930, compressed solid wood was produced under the trade name "Lignostone" in Germany, and it is still being produced by Röchling Group, Germany and by Lignostone ${ }^{\circledast}$, Netherlands (Kutnar et al. 2015).

Seborg et al. (1945) found that a density of $1300 \mathrm{~kg} \mathrm{~m}^{-3}$ could be achieved at a pressure of 10-17 MPa on birch laminates, depending on the plasticising conditions. This product is called "Staypak" and the purpose was to improve the mechanical properties with a focus on hardness and abrasion resistance. The temperature applied for Staypak was not high enough to give a long-term dimensional stability if the product was moistened. An additional problem was that the compressed wood must be cooled to below $100{ }^{\circ} \mathrm{C}$ under full pressure in order to avoid an elastic spring-back effect (Kollmann et al. 1975). In the following decades, many studies into the densification of wood followed (Kollmann et al. 1975, Navi et al. 2000, Kutnar \& Sernek 2007, Neyses et al. 2016). Already in 1968, Tarkow and Seborg published a study on the densification of only a few millimetres of wood cells directly beneath the surface of a board, while the core remained in its original state (Tarkow \& Seborg 1968). For certain applications, such as wood flooring and table tops, the combination of a hard surface and a relatively soft core with proper damping characteristics is more suitable than a board that is densified through its entire thickness.

For the most part, studies into the surface densification of wood have focused on batch processes to understand the influence of the process parameters on the properties, especially the density profile of the surface-densified wood. Rautkari et al. (2011) studied the relationship between the density profile of the densified wood and the compression ratio, pressing temperature, and pressing time. They found that shorter pressing times and lower temperatures led to a density profile with a high density peak close to the wood surface. Laine et al. (2014) examined the microscopic structure of the wood cells after densification. As in the study of Rautkari et al. (2010), the most pronounced density profile was obtained at pressing temperatures of 150 to $200{ }^{\circ} \mathrm{C}$ and press closing times of 30 to $60 \mathrm{~s}$. The surface densification of aspen at a pressing temperature of $145^{\circ} \mathrm{C}$ with a total pressing time of $12 \mathrm{~min}$ led to an almost doubled surface hardness (Gong et al. 2010). Laine et al. (2013a) obtained a similar hardness increase after densifying Scots pine at a pressing temperature of $150^{\circ} \mathrm{C}$ and a closing time of $30 \mathrm{~s}$. In a similar experiment, it was found that the compression ratio had no significant effect on the resulting hardness (Rautkari et al. 2013).

From a technological perspective, the existing studies provide a decent understanding of both the gross and the surface densification of wood. However, these studies did not take into account industrial implementation aspects such as process costs and time consumption. For example, "Compreg" type plywood is commercially available, but only at prices almost an order of magnitude higher than those of its undensified counterpart. In an attempt to develop a more industrially applicable process, Neyses et al. (2016) introduced a continuous roller pressing process with a speed of up to $80 \mathrm{~m} \mathrm{~min}^{-1}$. This process could compress the surface of Scots pine so that density profiles with a strong increase in density just beneath the surface were achieved.

When the load was removed from the compressed wood, the elastic deformation was instantaneously recovered and this recovery is called spring-back. The remaining deformation can be released if the wood is exposed to humidity (in the absence of an external force), and the densified wood then almost completely returns to its initial dimensions prior to the densification. This re-shaping of wood cells is called compression-set recovery, set-recovery, or shape memory (Morsing 2000, Navi \& Sandberg 2012). The fixation of compressive deformation in wood products, in particular the set-recovery, is a challenge. The set-recovery can be reduced or eliminated by thermo-hydro treatments or chemical modification, but is still one of the major obstacles, preventing the large-scale commercialization of surface-densified wood products.

In 1941, Stamm and Seborg developed a product called "Compreg": highly densified wood impregnated with phenol-formaldehyde resin, which successfully eliminates the set-recovery (Stamm \& Seborg 1941). Compreg has an even higher hardness and compressive strength than Staypak, but is more brittle and problematic from an environmental perspective. Gong et al. (2010) were able to eliminate the set-recovery of surface densified aspen almost entirely by a combined steam and heat post-treatment at $200{ }^{\circ} \mathrm{C}$ for 3 hours. Laine et al. (2013b) achieved similar results for surface densified Scots pine at the same treatment temperature. Acetylating wood before densification resulted in a reduction of the set-recovery from 70 to $20 \%$ (Laine et al. 2016).

Wood modification using silicon compounds has been studied by many researchers in order to improve fire retardancy, biological resistance and dimensional stability (Furuno \& Imamura 1998, Mai \& Militz 2004, Kartal et al. 2007, Altun et al. 2010, Ghosh et al. 2012). Sodium silicate $\left(\mathrm{Na}_{2} \mathrm{SiO}_{3}\right)$ solution, so-called "waterglass", is water-soluble and highly alkali. By applying $\mathrm{Na}_{2} \mathrm{SiO}_{3}$ to solid wood various changes in wood properties can be achieved. Basically, it is essential to fill the lumina of wood cells with the chemical (Mai \& Militz 2004).

Aqueous sodium hydroxide $(\mathrm{NaOH})$ has typically been used for alkali treatment on solid wood surfaces. Treatment with a high concentration of $\mathrm{NaOH}$ removes wood extractives from the wood matrix (Chen 1970) and crystalline cellulose is converted to cellulose II or III which can be more easily hydrolysed than native cellulose (Tolan 2006). $\mathrm{NaOH}$ generally increases the wettability of the wood surface and swells the wood structure (Christiansen 1990). This treatment also increases the number of hydroxyl groups on the wood fibre surface, so that the wood surface becomes more hydrophilic (Dai \& Fan 2014). $\mathrm{NaOH}$ can interrupt interaction between the wood components by hydrolysing ester bonds between fatty acids and cellulose, which results in the sodium salt of the carboxylic acid becoming more soluble (Christiansen 1990).

Recently, so-called "ionic liquids" have been studied for dissolving cellulose and wood (Swatloski et al. 2002, Kilpeläinen et al. 2007, Sun et al. 2009). Ionic liquids are seen as "green solvents" and are organic salts with a melting temperature below 100 ${ }^{\circ} \mathrm{C}$. Apart from their ability to dissolve cellulose, several studies report positive effects on antifungal and antimicrobial activity, and on fire and UV degradation resistance (Pernak et al. 2003, Patachia et al. 2012, Foksowicz-Flaczyk \& Walentowska 2013, Miyafuji \& Fujiwara 2013).

Ou et al. (2014) used various ionic liquids to plasticise poplar wood and measured the level of plasticisation with the help of a nonisothermal compression technique. According to the authors, treatment with ionic liquids transformed the wood - including crystalline cellulose - into a thermoplastic material, which means that upon reaching a certain temperature it can be deformed plastically, without or only little elastic deformation. In this way, the set-recovery can possibly be reduced, or even prevented from occurring in the first place. 1-Ethyl-3-methylimidazolium chloride apparently had the strongest effect as a plasticiser of the four ionic liquids tested.

In alignment to the development of a high-speed surface densification process, the objective of the present study was to assess the efficacy of fast pre-treatment techniques for surface-densified Scots pine in order to reduce the set-recovery and increase the hardness:

- Sodium silicate to fill the cell lumen and subsequently polymerise and stabilise the densified wood and increase its hardness.

- Methacrylate ester monomers to fill the cell lumen, and subsequently polymerise and stabilise the densified wood and increase its hardness. Generally, this impregnation treatment is supposed to work in a similar way as the treatment with Sodium silicate.

- Sodium hydroxide for the activation of 
hydroxyl groups to lower the set-recovery.

- Ionic liquid (1-Ethyl-3-methylimidazolium chloride) to eliminate internal stresses by plasticising crystalline cellulose. The expected plasticising effect could lead to extreme deformations, which would have a positive effect on the hardness.

\section{Materials and methods}

\section{Specimen preparation}

Specimens were cut from Scots pine ( $\mathrm{Pi}$ nus sylvestris L.) boards obtained from northern Sweden and conditioned in a climate chamber at a temperature of $20^{\circ} \mathrm{C}$ and $65 \%$ relative humidity to reach an average moisture content (MC) of $13-14 \%$. The conditioned specimens were sawn to a width of $25 \mathrm{~mm}$ (tangential) and planed to a thickness of $17 \mathrm{~mm}$ (radial). The two different specimen lengths of $149 \mathrm{~mm}$ and 120 $\mathrm{mm}$ were chosen because of the platen dimensions of the two different hot presses used for the surface densification. The specimens were cut so that the densified side did not contain any heartwood or knots. The annual growth rings were oriented between $0^{\circ}$ (horizontal) and approx. $30^{\circ}$ to the surface to be densified, and the density of the untreated specimens varied between $420 \mathrm{~kg} \mathrm{~m}^{-3}$ and $520 \mathrm{~kg} \mathrm{~m}^{-3}$. After cutting the specimens, they were randomised and grouped according to the type of treatment. The densification and chemical treatments were carried out in two different experiments, one at Aalto University in Finland, the other at Luleå University of Technology in Sweden (Fig. 1).

\section{Experimental procedure}

All the treatments were applied to one side of the specimens before the surface densification. The specimens were densified in the radial direction in an open system, consisting of two platens attached to a press, of which the lower platen can be heated and cooled (Fig. 2). By compressing the specimens to a target thickness of 15 $\mathrm{mm}$, a compression ratio of $12 \%$ was achieved. The specimens were grouped according to their respective treatments:

- CA: untreated control specimens at Aalto University;

- CL: untreated control specimens at Luleå University;

- DA: untreated, densified specimens at Aalto University;

- DL: untreated, densified specimens at Luleå University;

- SS 20-100: treated with sodium silicate at $20,40,50,80$ or $100 \%$ concentration by volume, no densification;

- DSS 20-100: treated with sodium silicate at $20,40,50,80$ or $100 \%$ concentration by volume, surface-densified;

- DSH 0.4-8: treated with sodium hydroxide at $0.4,4$ or $8 \%$ concentration by volume, surface-densified;

- DI 10-20: treated with ionic liquid at 10 or $20 \%$ concentration by weight, surface-

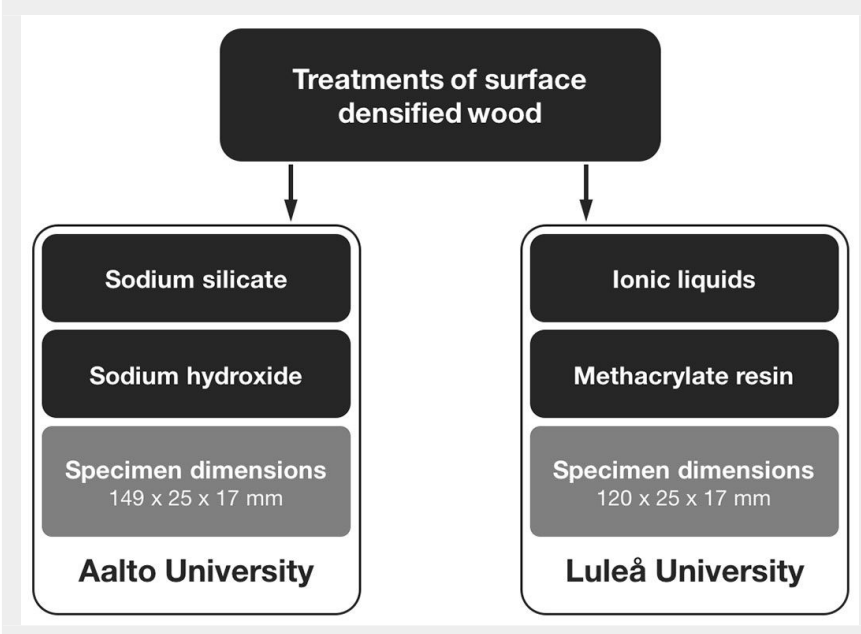

Fig. 1 - Overview of the two surface densification experiments and the respective dimensions of the specimens.

densified;

- DM: treated with methacrylate resin, surface-densified.

\section{Untreated and densified specimens: DA and DL}

The specimens in groups DA and DL were not treated before densification. Group DA was densified at $130^{\circ} \mathrm{C}$ with a closing speed of $0.067 \mathrm{~mm} \mathrm{~s}^{-1}$, followed by a holding time of $60 \mathrm{~s}$, and a cooling period of about $60 \mathrm{~s}$, to a temperature below $100{ }^{\circ} \mathrm{C}$. Densifying Scots pine in this way leads to a densification of the wood cells beneath the surface that is in contact with the heated press platen, while the core and the wood cells close to the opposite surface largely remain in their initial, uncompressed state.

Due to limitations regarding the minimum closing speed of the pressing equipment at Luleå University, the densification regime was adjusted. At first, the specimens were put on the heated platen $\left(150^{\circ} \mathrm{C}\right)$ for $30 \mathrm{~s}$ without pressure, after which a pressure of $1 \mathrm{MPa}$ was applied with a closing speed of $2.5 \mathrm{~mm} \mathrm{~s}^{-1}$ and held for $45 \mathrm{~s}$. Subsequently the pressure was increased to $4 \mathrm{MPa}$ with a closing speed of $2.5 \mathrm{~mm} \mathrm{~s}^{-1}$, which resulted in compression to the target thickness of $15 \mathrm{~mm}$. The pressure was held for $30 \mathrm{~s}$, followed by cooling to below $100{ }^{\circ} \mathrm{C}$, which took another $90 \mathrm{~s}$.

The thickness of the specimens was mea- sured with a digital calliper before and after the densification process, so that the spring-back after densification could be determined. The groups DA and DL consisted of 15 specimens each.

\section{Sodium silicate treatment: SS 20-100 and DSS 20-100}

The sodium silicate $\left(\mathrm{Na}_{2} \mathrm{SiO}_{3}\right)$ solution as supplied by the producer (Merck KGaA 105621 sodium silicate solution) contained $35 \%$ of pure sodium silicate. This solution was dissolved in water at different volume concentrations (20,40,50,80 and $100 \%$ sodium silicate solution) prior to the treatment.

The resulting aqueous solutions were applied to the wood surface with a paper towel, so that the surface was entirely wetted. After $30 \mathrm{~s}$ waiting time, excess liquid on the wood surface was wiped off with another dry paper towel. To determine the mass gain, the specimens were weighed before and after impregnation.

The groups DSS 20-100 were densified in the same way as group DA, as described above. The groups SS 20-100 consisted of 5 specimens each, while the groups DSS 20100 consisted of 15 specimens per concentration.

\section{Methacrylate resin impregnation: DM}

The methacrylate resin (TurnTex Wood-

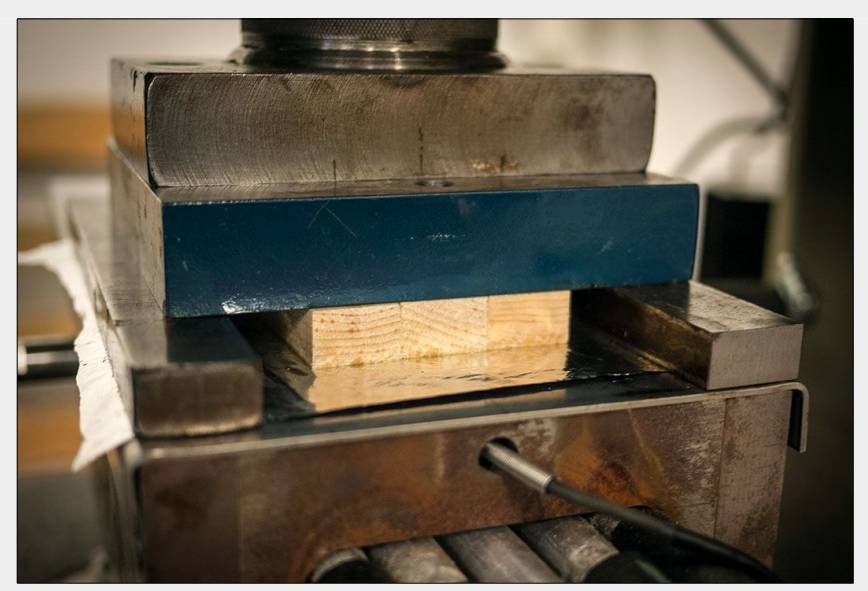

Fig. 2 - The densification equipment used at Aalto University. The lower press platen can be heated and cooled. 
works Cactus Juice Resin) was applied with a dry paper towel until the wood surface was completely wetted. After 5 minutes, the procedure was repeated, followed by another 5 minutes waiting time.

The densification process was carried out in the same way as for group DL, as described above. Group DM consisted of 15 specimens.

\section{Sodium hydroxide treatment: DSH 0.4-8}

The sodium hydroxide ( $\mathrm{NaOH}$ - Merck 1.06495.0250) was dissolved in water to obtain aqueous solutions with volume concentrations of $0.4,4$ and $8 \%$. The sodium hydroxide solutions were applied in the same way as the sodium silicate solutions and the densification process was carried out as for group DA, described above. The groups DSH 0.4-8 consisted of 15 specimens for each concentration.

\section{Ionic liquid treatment: $\mathrm{DI}$ 10-20}

1-Ethyl-3-methylimidazolium chloride of $97 \%$ purity was dissolved in ethanol to obtain weight concentrations of 10 and $20 \%$. As the expected effect of the ionic liquid solution is compromised by the presence of water, it was applied to oven-dried specimens with the help of a dry paper towel until the wood surface was completely wetted. After 10 minutes, the procedure was repeated, followed by another $10 \mathrm{~min}$ utes waiting time.

The densification process was carried out as for group DL, but at a temperature of $200{ }^{\circ} \mathrm{C}$, to ensure that the treated wood would be sufficiently plasticised. Due to the higher press platen temperature, the cooling period lasted for approx. $120 \mathrm{~s}$. The groups DI 10-20 consisted of 15 specimens for each concentration.

Set-recovery determination was measured after one and two cycles of soaking in water for $24 \mathrm{~h}$ at $20^{\circ} \mathrm{C}$, followed by oven-drying at $103^{\circ} \mathrm{C}$ for $24 \mathrm{~h}$. The setrecovery is defined as (eqn. 1):

$$
R_{s}=\frac{R^{\prime}{ }_{c}-R_{c}}{R_{0}-R_{c}}
$$

where $R_{0}$ is the thickness of the specimen before densification, $R_{c}$ is the thickness of the specimen after densification and $R^{\prime}{ }_{c}$ is the thickness of the densified sample after the recovery period. Set-recovery can vary between $0 \%$ and $100 \% . R=0 \%$ indicates that there is no shape memory or that the compression-set is completely fixed, and when $R=100 \%$, the recovery is total. When the specimen is not totally fixed, $\mathrm{R}$ will take some value between $0 \%$ and $100 \%$. The problem in this way of calculating the setrecovery is that the initial, uncompressed oven-dry thickness was not known for specimens that were densified at a moisture content of $13-14 \%$. For this reason, a test set of specimens, cut to the same dimensions and with the same annual ring orientation in the cross section was ovendried. The average shrinkage percentage in the radial direction of these specimens was applied to the other specimens to extrapolate their oven-dry thickness before compression. In this way, the set-recovery phenomenon is separated from the regular moisture-induced shrinkage of wood. Applying the simulated average shrinkage to the test set resulted in a difference between real and simulated oven-dry thicknesses of less than $0.02 \mathrm{~mm}$.

\section{Hardness determination}

The Brinell hardness measurements were made in accordance with the standard EN1534 but with several modifications. A Zwick Roell ZwickiLine 2.5 TS universal testing machine equipped with a $2.5 \mathrm{kN}$ load cell and a steel ball with a diameter (D) of
$10 \mathrm{~mm}$ was used. The force was increased at a rate of $4 \mathrm{kN}$ per minute to a nominal force (F) of $1 \mathrm{kN}$, which was held for $25 \mathrm{~s}$ before being released.

According to the standard, the Brinell hardness is calculated from the diameter of the indentation in the specimen. In this case, however, the Brinell hardness was calculated from the depth of the indentation. The reason for this modification is the difficulty of measuring the diameter of the indentation in wood. In contrast to steel or other metals, wood does not leave an indentation with a clear border. The depth of the indentation ( $h$ ) can be, however, measured with high accuracy and precision by the hardness testing equipment. For the same reason, Niemz \& Stübi (2000) and Laine et al. (2013a) previously implemented a similar approach. Thus, the Brinell hardness (HB) is here defined as (eqn. 2):

$$
H B=\frac{F}{\pi D h}
$$

A total of 30 hardness measurements were made on each group, except for those that were treated with sodium silicate, but not densified (SS 20-100). For these four groups, only 10 measurements each were made.

\section{Effect of treatments on wood colour}

Colour changes caused by the treatments and the densification process were assessed in a qualitative way by visual inspection.

\section{Results}

The objective of the study was to determine the effect of various chemical and impregnation treatments on the set-recovery and hardness of surface-densified Scots pine. The following sub-sections present the main results.

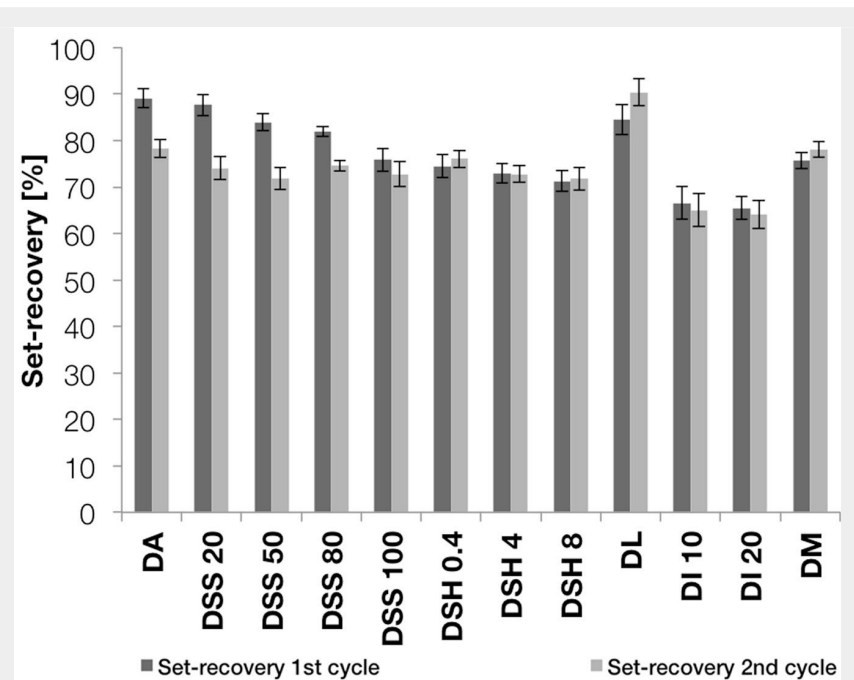

Fig. 3 - The mean set-recovery of all groups after one and two wet-dry cycles. The error bars show the standard deviation of each group.

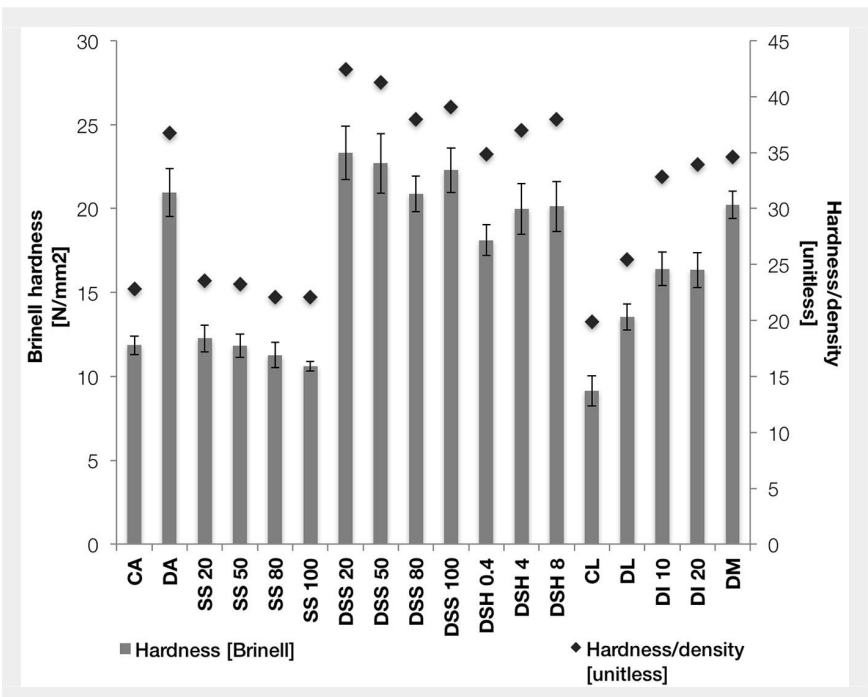

Fig. 4 - The Brinell hardness (left-hand ordinate, grey bars) and the ratio between hardness and density (right-hand ordinate, black diamonds) for all groups. The error bars show the standard deviation of each group. 
Elastic spring-back and set-recovery

The elastic spring-back upon releasing the pressure after the cooling period was between $10 \%$ and $20 \%$ for all specimens, regardless of the applied treatment. Fig. 3 presents the mean set-recovery after wetdry cycling. For groups DA and DSS 20-100, the set-recovery decreased between the first and second wet-dry cycle. In general, the effect of the pre-treatment with sodium silicate was rather small. The treatment with sodium hydroxide led to a slightly greater reduction in set-recovery, and a high solution concentration seemed to slightly increase this effect. In the case of the sodium silicate treatment, there was no significant difference between the effects of the tested concentrations. Methacrylate resin impregnation reduced the set-recovery by $10-15 \%$.

The treatment with the ionic liquid led to the greatest reduction in set-recovery. After the second dry-wet cycle the set-recovery was about $65 \%$ in both groups and it remained stable between the first and second wet-dry cycles.

\section{Brinell hardness}

In Fig. 4 the mean hardness of all specimen groups is indicated by the left-hand ordinate. To cancel out the influence of density variations on the results, the righthand ordinate shows the ratio between hardness and density (black diamonds).

The sodium silicate treatment did not influence the hardness of the undensified specimens. Densifying the specimens almost doubled the hardness compared to the undensified specimens. The group DSS 20 had a 10\% higher hardness than the densified specimens without treatment (DA). Higher concentrations of sodium silicate led to a smaller increase in hardness. The specimens treated with sodium hydroxide had a slightly lower hardness than the group DA.

The hardness increase of group DL in relation to group $C L$ is lower than the hardness increase of group DA in relation to group CA. Visual inspection of the cross-sections of the specimens showed that the density peaks of group DL were not as close to the surface as the density peaks of group DA. In relation to group $\mathrm{DL}$, the specimens treated with ionic liquid solutions (DI 10 and DI 20) and methacrylate resin (DM) exhibited hardness increases of $20 \%$ and $50 \%$, respectively. Taking into account the density of the specimens does not alter the observations related to the hardness.

Regardless of the type of treatment, the densification carried out at Luleå University yielded lower hardness values than the densification at Aalto University.

The raw data of the hardness tests were examined to extract information about the material behaviour during the application of the test force (Fig. 5). The shallower the slope of the curve, the higher is the resulting hardness. During the first $15 \mathrm{~s}$ when the force is gradually increased to $1 \mathrm{kN}$, the

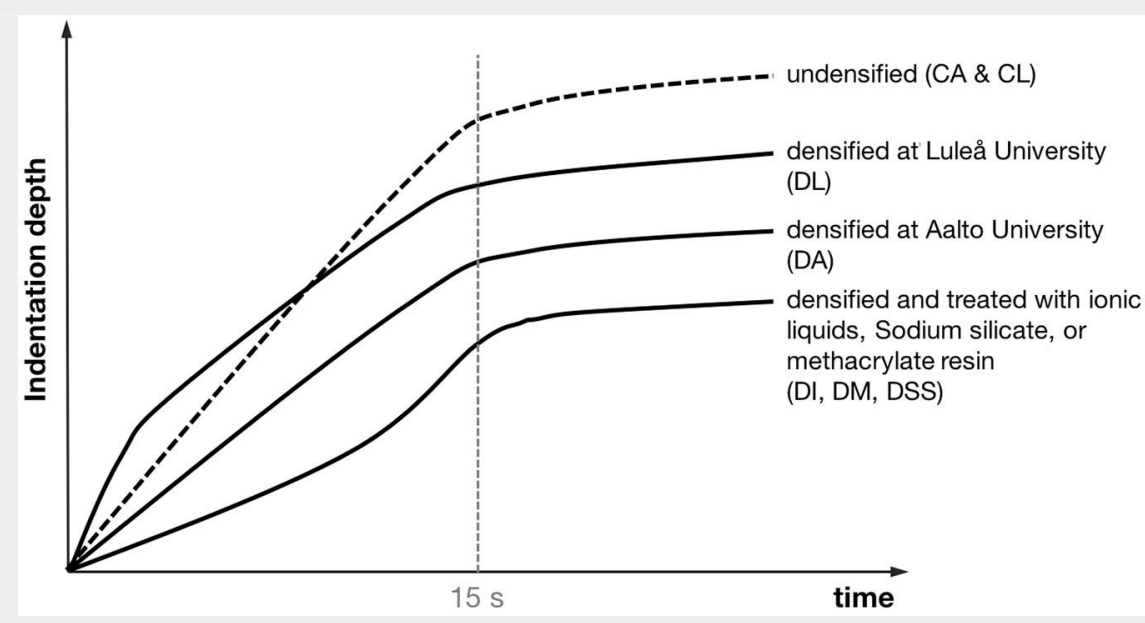

Fig. 5 - Behavior of the specimens during the Brinell hardness testing. During the first $15 \mathrm{~S}$ the loading force ramps up to $1 \mathrm{kN}$, after which it is held constant for another 25 s. The shallower the slope of a curve, the higher is the resulting hardness.

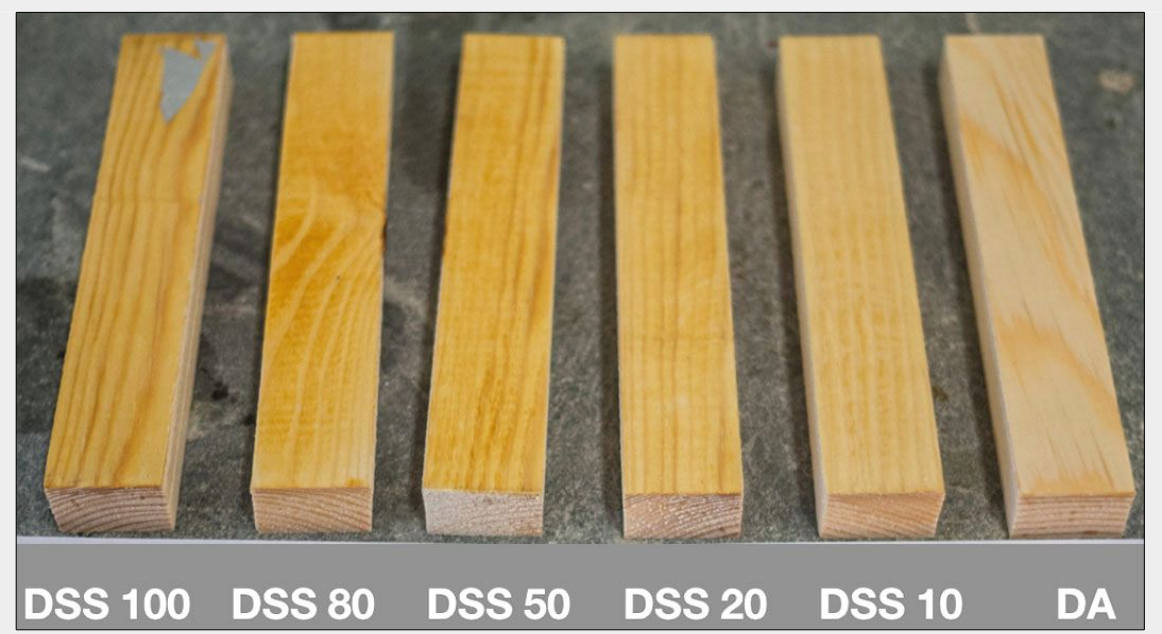

Fig. 6 - Colour changes on densified Scots pine caused by treatment with sodium silicate at $10,20,40,50,80$ or $100 \%$ concentration by volume. Because of the insignificance of the effects, DSS 10 was not further considered in any of the results.

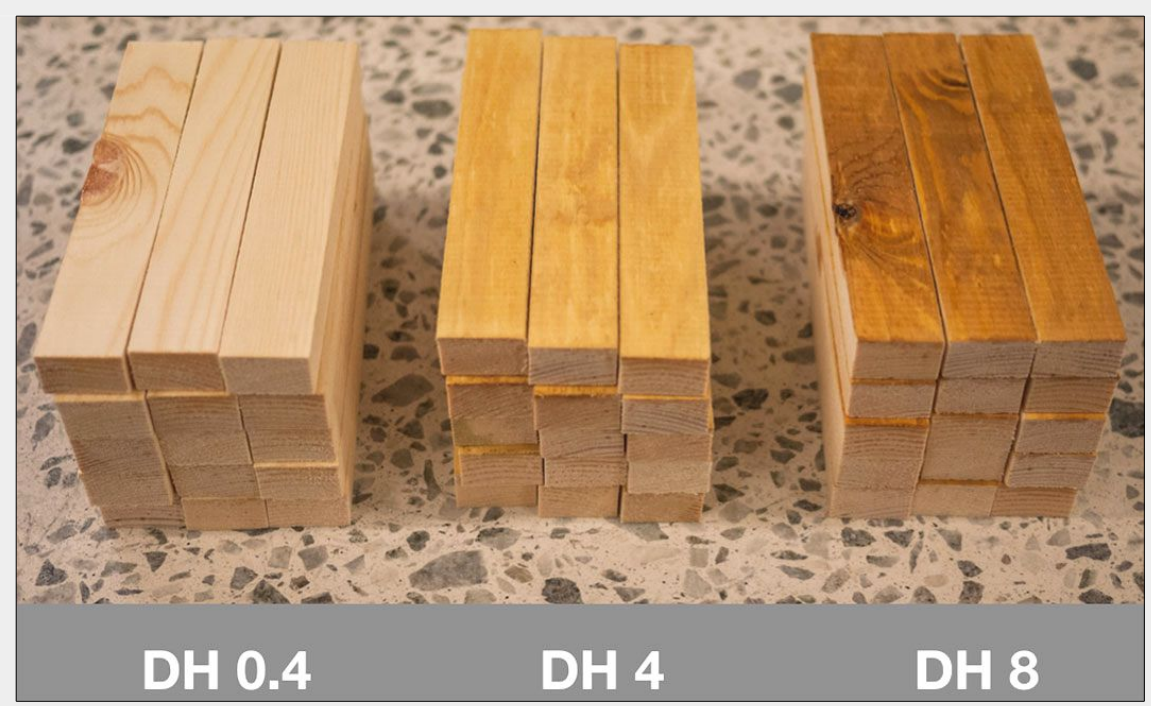

Fig. 7 - Colour changes on densified Scots pine caused by treatment with sodium hydroxide at $0.4,4$ or $8 \%$ concentration by volume. 


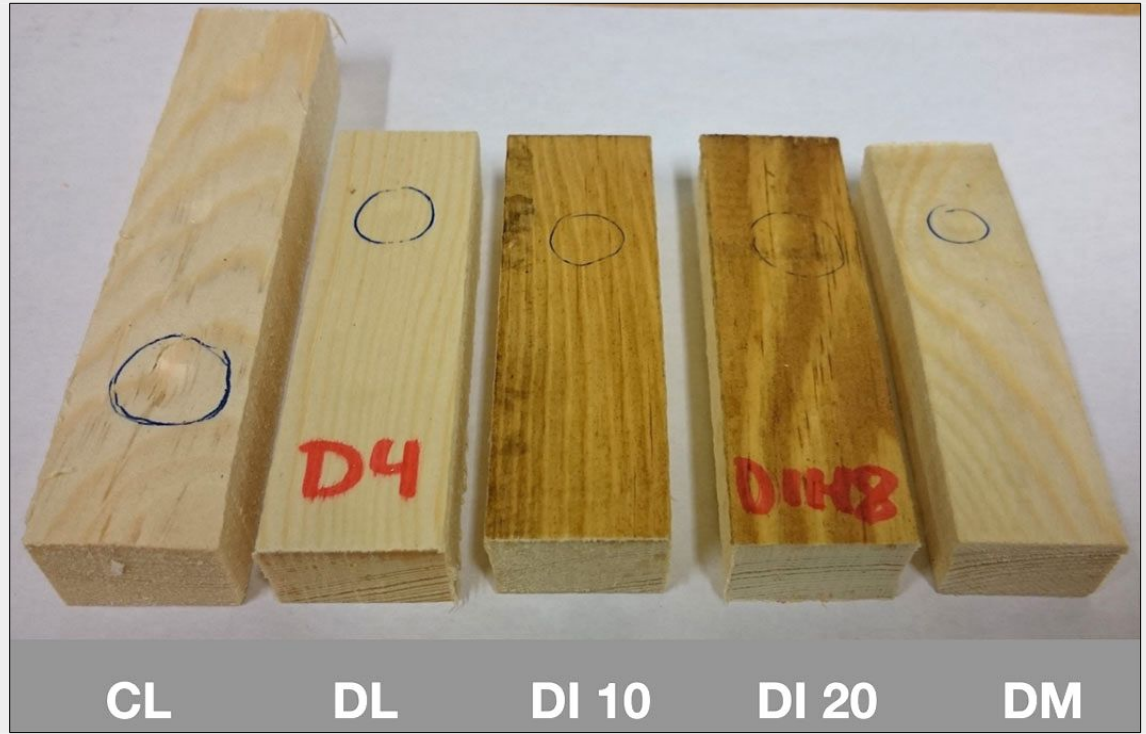

Fig. 8 - Colour changes on densified Scots pine caused by treatment with ionic liquid (DI 10 and DI 20) or methacrylate resin (DM). Non-densified (CL) and densified (DL) specimens without any treatment.

curve of indentation depth with time is fairly straight for the specimens without pre-treatment densified at Aalto university (DA). In contrast, the specimens densified at Luleå University (DL) exhibit a rapid progression of the indentation depth during the first few seconds, after which the curves flatten to a slope similar to that of the specimens densified at Aalto University (DA). The curves of the specimens treated with ionic liquids, sodium silicate or methacrylate resin start at a rather shallow angle that becomes steeper during the second half of the force increase period.

\section{Colour changes in the treated wood}

Fig. 6, Fig. 7, and Fig. 8 show the colour changes caused by the pre-treatments. Because of the insignificance of the effects, DSS 10 (Fig. 6) was not further considered in any of the results. The treatment with sodium silicate resulted in a slight colour change towards a more golden hue, which increased with the concentration of the solution. The treatment with sodium hydroxide led to a slight darkening of the wood at the two lower concentrations. The $8 \%$ solution had a rather strong darkening effect. Similar changes were observed in the spec- imens treated with ionic liquid, whereas the treatment with methacrylate resin led to only a slight colour change towards a more yellowish hue.

\section{Discussion}

\section{Elastic spring-back and set-recovery}

It is surprising that the set-recovery of groups DA and DSS 20-100 decreased between the first and second wet-dry cycles. The existing data do not provide an explanation for this behaviour. The apparent reduction of the set-recovery by pre-treatment with sodium silicate or sodium hydroxide after one wet-dry cycle was very small after two cycles. This phenomenon was not observed with the specimens densified at Luleå University, despite the fact that all the specimens were cut from the same batch of boards. Nor was it possible to observe a clear correlation between the concentration of sodium silicate and the set-recovery. The higher viscosity of the highly concentrated sodium silicate solutions (DSS 80 and DSS 100) made it more difficult for the solution to penetrate into the wood material and the solution with the higher concentration had no effect on the set-recovery.

In the case of the treatment with sodium hydroxide, a high concentration seemed to slightly increase the effect on the set-recovery, at least between the groups DH 0.4 and $\mathrm{DH} 4$.

The treatment with ionic liquid solutions had the strongest effect on the set-recovery of all the studied treatments. The difference between the two concentration levels was however insignificant, but the results are in line with the hypothesis that ionic liquids are able to plasticise cellulose, and thus reduce internal stresses caused by the cell wall deformation during the densification process (Kilpeläinen et al. 2007, Ou et al. 2014). In a pre-study in which the ionic liquid treatment was tested without a cooling period after densification, the treatment reduced the elastic springback from $60 \%$ to $30 \%$. This suggests that there is less elastic deformation in the cellulose that can recover, even though the surrounding lignin-hemicellulose matrix is still plasticised. The question is, however, to what extent the observed reduction in the set-recovery can be attributed to thermal degradation of wood components, caused by the press platen temperature of $200^{\circ} \mathrm{C}$.

The impregnation with methacrylate resin led only to a rather small reduction in set-recovery. As in the case of the very low efficacy of the treatment with sodium silicate, this could be due to insufficient penetration into the wood surface and insufficient weight gain. Both aspects could possibly be resolved with applying sodium silicate or the methacrylate resin in another way. Further studies are needed to test this hypothesis.

\section{Brinell hardness}

The results clearly show that a marked increase in hardness was achieved by densifying the specimens. The measured hardness of the group DA is in line with the values obtained by Laine et al. (2013a), even though the densification process parameters were not entirely the same. These authors suggested to reduce the pressing temperature and the press closing time to see whether this leads to even higher hardness values. In the present study, the pressing temperature was in fact $20{ }^{\circ} \mathrm{C}$ lower.

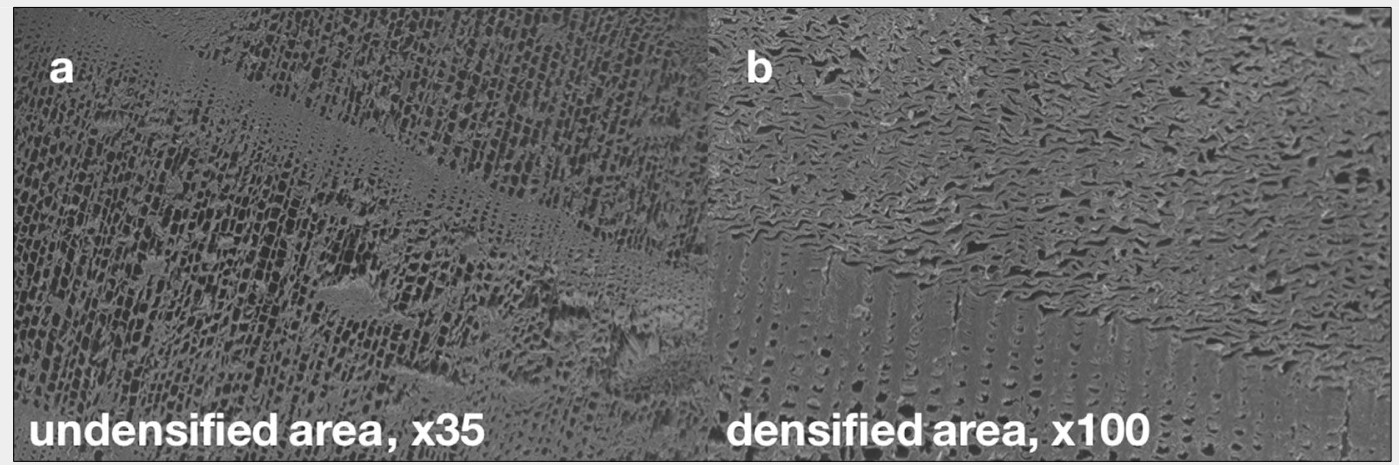

Fig. 9 - Scanning electron microscope (SEM) images of a specimen treated with $20 \%$ ionic liquid solution. The lefthand (a) side shows the undensified core of a specimen, while the right-hand (b) side shows densified cells close to the surface. 
However, the objective of this study was to determine the effect of chemical and impregnation treatments on the resulting hardness of the densified wood. The effect of the sodium silicate treatment is somewhat complex to understand. Group DSS 20 had a ten percent higher hardness than group DA, although the density was marginally lower. The results for the groups DSS 50 and DSS 80 suggest that there is a reduction in hardness with increasing concentrations of sodium silicate. This observation is supported by the measured densities, which are almost identical between these groups. It can be explained by the lower mass gain with higher concentrations of sodium silicate. The lower mass gain is probably due to the high viscosity of the highly concentrated sodium silicate solutions, which hampers the penetration of the solution into the wood surface. The increase in steepness of the curve of indentation depth over time illustrated in Fig. 5 is in accordance with this hypothesis. For low concentrations of sodium silicate, where penetration did not seem to be an issue, the transition between the shallow and steep parts was rather smooth and less severe than at high concentrations (DI, DM, DSS - Fig. 5).

The densified specimens treated with $100 \%$ sodium silicate solution (group DSS 100) showed however, an increase in hardness compared to the specimens treated with the $50 \%$ and $80 \%$ sodium silicate solutions. In this case, the solution possibly hardly penetrates the wood surface - because of its high viscosity - and polymerises to a thin but hard shell on top of it. This hard shell would work as an initial, resistant barrier, resulting in a slight overall hardness increase. The shape of the curve of indentation depth over time (Fig. 5; DSS) supports this hypothesis. Initially, for about five seconds, the curve is comparably shallow, before it becomes steeper in a somewhat abrupt manner. However, the available data are too weak to draw a definitive conclusion. Further chemical analyses are needed.

Pre-treatment of the densified specimens with sodium hydroxide appears to result in a lower hardness than the untreated and densified specimens. The weakest concentration of sodium hydroxide yielded the lowest hardness. However, taking into account the measured densities, the observed effect of the treatment on the hardness is at best very marginal. There might be an effect of wood degradation caused by the treatment, which is supported by the rather severe colour change in the specimens treated with the $8 \%$ sodium hydroxide solution.

Interestingly, the hardness values of the groups densified at Luleå University were in general lower than those obtained at Aalto University. The densification process itself is probably one of the causes for this. In the case of the specimens densified at Luleå University (DL), the density peak was not at the surface, but about 1-2 $\mathrm{mm}$ beneath it. The shape of the curve of indentation depth with time, shown in Fig. 5 with a steep first part that later becomes shallower, supports this observation (DL). The treatments with ionic liquid and methacrylate resin clearly had a positive effect on the location of the density peak and the overall hardness in relation to group DL.

Fig. 9 shows scanning electron microscope (SEM) images of a specimen treated with the $20 \%$ ionic liquid solution. The lefthand (a) side shows the undensified core, while the right-hand side (b) shows densified cells close to the surface. It appears that the ionic liquid solution in fact works as a strong plasticizer, leading to strong increase in hardness. However, the hardness increase could potentially be higher with a deeper penetration into the wood surface. The hardness test curve indicates a behaviour similar to that of the sodium silicate treatment (DI and DSS - Fig. 5).

The positive effect on the hardness of the treatment with methacrylate is probably a result of a polymerised layer of the impregnation agent close to the densified wood surface. Based on the current data and past studies (Stamm \& Seborg 1941), there is no reason to believe that the treatment affected the plasticity of the wood or caused any other type of chemical wood modification.

\section{Conclusions}

The objective of this study was to assess the efficacy of chemical and impregnation pre-treatments of Scots pine prior to surface densification to reduce the set-recovery and increase the hardness.

In general, the efficacy of the treatments with regard to the set-recovery was rather low, especially concerning sodium silicate and sodium hydroxide. The same applies to the impregnation treatment with methacrylate resin.

Chemically modifying the wood with an ionic liquid showed better results, despite an inadequate depth of penetration into the wood surface with the application method used. The reduction in set-recovery by almost 30\%, an increase in hardness, and the strong plasticising effect certainly warrant further studies with this type of chemical.

The densification of the wood surface almost doubled the hardness compared to that of the undensified specimens. Pretreatment of the wood with low concentrations of sodium silicate resulted in a small but significant increase in hardness after densification. Increasing the concentration level did not yield a higher hardness, probably because higher viscosities hindered penetration into the wood surface. Treatment with sodium hydroxide had no positive effect on the hardness.

Apart from leading to a reduction in setrecovery, the use of an ionic liquid as a plasticiser make possible a targeted increase in density very close to the surface of the densified wood. By controlling the depth of penetration, it should also be possible to control the depth of densification. These two factors potentially allow for a significant increase in hardness in comparison to untreated, densified wood.

\section{Acknowledgements}

BN planned and performed the majority of the experiments, conducted the analysis and was the main writer of the manuscript. LR supported the planning and conduction of the experiments at Aalto University. AY supported the conduction of the experiments at Aalto University and the writing process. DS supported the writing process.

Financial support from the COST Action FP1407 project, the Swedish Research Council Formas (project EnWoBio 2014172), and the Wood Centre North through the Träinnovation Norr project is gratefully acknowledged.

\section{References}

Altun S, Ozcifci A, Senel A, Baysal E, Toker H (2010). Effects of silica gel on leaching resistance and thermal properties of impregnated wood. Wood Research 55: 101-112. [online] URL: http://www.researchgate.net/publication/27221 7996

Chen CM (1970). Effect of extractive removal on adhesion and wettability of some tropical woods. Forest Products Journal 20: 36-41. [online] URL: http://www.cabdirect.org/cabdi rect/abstract/19700607243

Christiansen AW (1990). How overdrying wood reduces its bonding to phenol-formaldehyde adhesives - a critical-review of the literature. Part 1. Physical responses. Wood and Fiber Science 22: 441-459.

Dai D, Fan M (2014). Wood fibres as reinforcements in natural fibre composites: structure, properties, processing and applications. In: "Natural Fibre Composites: Materials, Processes and Properties". Woodhead Publishing Ltd, Cambridge, UK, pp. 3-65. [online] URL: http://books.google.com/books?id=GnXbAgAA QBAJ

Foksowicz-Flaczyk J, Walentowska J (2013). Antifungal activity of ionic liquid applied to linen fabric. International Biodeterioration and Biodegradation 84: 412-415. - doi: 10.1016/j.ibiod.20 12.05.025

Furuno T, Imamura $Y$ (1998). Combinations of wood and silicate. Part 6 . Biological resistances of wood-mineral composites using water glassboron compound system. Wood Science and Technology 32: 161-170. - doi: 10.1007/BFo070 4839

Ghosh SC, Peters BC, Fitzgerald CJ, Militz H, Mai $C$ (2012). Resistance of Scots pine (Pinus sylvestris L.) wood modified with functionalized commercial silicone emulsions against subterranean termites. Wood Science and Technology 46: 1033-1041. - doi: 10.1007/s00226-012-0464-0

Gong M, Lamason C, Li L (2010). Interactive effect of surface densification and post-heattreatment on aspen wood. Journal of Materials Processing Technology 210 (2): 293-296. - doi: 10.1016/j.jmatprotec.2009.09.013

Holzveredelung (1923). Verfahren zur Herstel- 
lung veredelten Holzes [A process for producing improved wood]. Holzveredelung G.m.b.H. in Berlin, Reichspatentamt, Patentschrift nr. 357385, Berlin, Germany.

Kartal SN, Hwang W, Yamamoto A, Tanaka M, Matsumura K, Imamura Y (2007). Wood modification with a commercial silicon emulsion: effects on boron release and decay and termite resistance. International Biodeterioration and Biodegradation 60: 189-196. - doi: 10.1016/j.ibio d.2007.03.002

Kilpeläinen I, Xie H, Kin A, Granstrom M, Heikkinen S, Argyropoulos DS (2007). Dissolution of wood in ionic liquids. Journal of Agricultural and Food Chemistry 55 (22): 9142-9148. - doi: 10.1021/jfo71692e

Kollmann FFP, Kuenzi EW, Stamm AJ (1975). Principles of wood science and technology. Vol. II: wood based materials. Springer-Verlag, Berlin/Heidelberg, Germany, pp. 141-148.

Kutnar A, Sernek M (2007). Densification of wood. Zbornik Gozdarstva in Lesarstva 82: 5362. [online] URL: http://eprints.gozdis.si/198/

Kutnar A, Sandberg D, Haller P (2015). Compressed and moulded wood from processing to products. Holzforschung 69 (7): 885-897. - doi: 10.1515/hf-2014-0187

Laine K, Rautkari L, Hughes M (2013a). The effect of process parameters on the hardness of surface densified Scots pine solid wood. European Journal of Wood and Wood Products 71: 13-16. doi: 10.1007/s00107-012-0649-0

Laine K, Rautkari L, Hughes M, Kutnar A (2013b). Reducing the set-recovery of surface densified Scots pine wood by hydrothermal post-treatment. European Journal of Wood and Wood Products 71: 17-23. - doi: 10.1007/s00107-012-06 47-2

Laine K, Segerholm K, Wålinder M, Rautkari L, Ormondroyd G, Hughes M, Jones D (2014). Micromorphological studies of surface densified wood. Journal of Materials Science 49 (5): 2027-2034. - doi: 10.1007/s10853-013-7890-8

Laine K, Segerholm K, Wålinder M, Rautkari L, Hughes M, Lankveld C (2016). Surface densification of acetylated wood. European Journal of Wood and Wood Products 74 (6): 829-835. doi: 10.1007/s00107-016-1077-3

Mai C, Militz H (2004). Modification of wood with silicon compounds. inorganic silicon compounds and sol-gel systems: a review. Wood Science and Technology 37: 339-348. - doi: 10.1007/soo226-003-0205-5

Miyafuji H, Fujiwara Y (2013). Fire resistance of wood treated with various ionic liquids (ILs). Holzforschung 67: 787-793. - doi: 10.1515/hf-20 12-0166

Morsing N (2000). Densification of wood: the influence of hygrothermal treatment on compression of beech perpendicular to the grain. PhD Dissertation, Technical University of Denmark, Copenhagen, Denmark, pp. 22.

Navi P, Girardet F, Heger F (2000). Thermohydro-mechanical post-treatment of densified wood. In: Proceedings of " 5 " Pacific Rim BioBased Composites Symposium". Canberra (Australia) 10-13 Dec 2000, pp. 439-447.

Navi P, Sandberg D (2012). Thermo-hydro-mechanical processing of wood. EPFL Press, Lausanne, Switzerland, pp. 216-222. [online] URL: http://books.google.com/books?id=wO3-HP5IC $\mathrm{XoC}$

Neyses B, Hagman O, Nilsson A, Sandberg D (2016). Development of a continuous wood surface densification process - the roller pressing technique. In: Proceedings of the " $59^{\text {th }}$ SWST International Convention”. Curitiba (Brazil) 6-10 Mar 2018, pp. 1-10. [online] URL: http://www. diva-portal.org/smash/get/diva2:1003972/FULL TEXT01.pdf

Niemz P, Stübi T (2000). Investigations of hardness measurements on wood based materials using a new universal measurement system. In: Proceedings of the Symposium "Wood Machining. Properties of Wood and Wood Composites Related to Wood Machining" (Stanzl-Tschegg SE, Reiterer A eds). Vienna (Austria) 27-29 Sept 2000, pp. 51-61. [online] URL: http://www. map.boku.ac.at/fileadmin/data/H03000/H8900 o/H89200/Downloads/Proceedings_1_ISWM_2 0oo.pdf\#page $=59$

Ou R, Xie Y, Wang Q, Sui S, Wolcott MP (2014). Thermoplastic deformation of poplar wood plasticized by ionic liquids measured by a nonisothermal compression technique. Holzforschung 68 (5): 555-566. - doi: 10.1515/hf-2013-01 36

Patachia S, Croitoru C, Friedrich C (2012). Effect of UV exposure on the surface chemistry of wood veneers treated with ionic liquids. Applied Surface Science 258: 6723-6729. - doi: 10.1016/j.apsusc.2011.12.050

Pernak J, Sobaszkiewicz K, Mirska I (2003). Antimicrobial activities of ionic liquids. Green Chem- istry 5 (1): 52-56. - doi: 10.1039/b207543C

Rautkari L, Properzi M, Pichelin F, Hughes M (2010). Properties and set-recovery of surface densified Norway spruce and European beech. Wood Science and Technology 44: 679-691. doi: 10.1007/s00226-009-0291-0

Rautkari L, Laine K, Laflin N, Hughes M (2011). Surface modification of Scots pine: the effect of process parameters on the through thickness density profile. Journal of Materials Science 46: 4780-4786. - doi: 10.1007/s10853-0115388-9

Rautkari L, Laine K, Kutnar A, Medved S, Hughes $M$ (2013). Hardness and density profile of surface densified and thermally modified Scots pine in relation to degree of densification. Journal of Materials Science 48: 2370-2375. - doi: 10.1007/s10853-012-7019-5

Sears CU (1900). Process of preparing wood matrices. US Patent no. 646547, Washington, DC, USA, pp. 3. [online] URL: http://www.goog le.com/patents/US646547

Seborg RM, Millet MA, Stamm AJ (1945). Heatstabilized compressed wood. Staypak. Mechanical Engineering 67: 25-31.

Stamm AJ, Seborg RM (1941). Resin-treated, laminated, compressed wood. Forest Products Laboratory, USDA Forest Service, Madison, WI, USA, pp. 1-11. [online] URL: http://ir.library. oregonstate.edu/xmlui/bitstream/handle/1957/1 238/FPL_1268ocr.pdf

Sun N, Rahman M, Qin Y, Maxim ML, Rodríguez H, Rogers RD (2009). Complete dissolution and partial delignification of wood in the ionic liquid 1-ethyl-3-methylimidazolium acetate. Green Chemistry 11 (5): 646-655. - doi: 10.1039/b82270 $2 \mathrm{k}$

Swatloski RP, Spear SK, Holbrey JD, Rogers RD (2002). Dissolution of cellulose with ionic liquids. Journal of the American Chemical Society 124 (18): 4974-4975. - doi: 10.1021/ja02579om

Tarkow H, Seborg RM (1968). Surface densification of wood. Forest Products Journal 18 (9): 104-107.

Tolan JS (2006). logen's demonstration process for producing ethanol from cellulosic biomass. In: "Biorefineries-Industrial Processes and Products: Status Quo and Future Directions". Wiley-VCH Verlag GmbH, Weinheim, Germany, pp. 193-208. - doi: 10.1002/9783527619849.ch9 